\title{
INFLUENCE OF METAL SHRINKAGE IN LONGITUDINAL WELDS OF SLEEVES ON CONTACT PRESSURE IN MAIN GAS PIPELINE REPAIR
}

\author{
O.I. OLEJNIK \\ E.O. Paton Electric Welding Institute, NASU \\ 11 Bozhenko Str., 03680, Kiev, Ukraine. E-mail: office@paton.kiev.ua
}

\begin{abstract}
Effectiveness of main pipeline repair in service is largely determined by contact pressure, created at sleeve mounting on pipe defective section. At correct selection of contact pressure value, long-term performance of the repaired section is ensured through partial unloading of the pipe wall. Such a result is achieved due to lowering of pressure in the main line before repair, and tight pressing of the sleeve around the pipe with a special device. Arc welding of sleeve reinforcing elements also is of considerable importance, resulting in formation of contact pressure, caused by shrinkage of multilayer longitudinal butt welds. In the work computational method was used to study the influence of sleeve wall thickness and pipeline diameter on the magnitude of contact pressure caused by deposited metal shrinkage. It is shown that contact pressure caused by metal shrinkage during welding performance has the strongest influence on unloading of a defective pipe wall in pipelines of $1020 \mathrm{~mm}$ and smaller outer diameter. Further increase of contact pressure magnitude caused by metal shrinkage can be achieved by increasing sleeve wall thickness. Such a technique is not effective for pipes of $1220 \mathrm{~mm}$ and greater diameter. 5 Ref., 5 Figures.
\end{abstract}

Keywords: main gas pipeline, sleeve, repair, arc welding, deposited metal shrinkage, contact pressure

Keeping Ukrainian gas transportation system in the appropriate technical condition by repair welding without taking the damaged sections out of service is an important scientific-practical task. Technologies involving application of reinforcing welded sleeves currently prevail in practical repair of corrosion damage of pipes of main gas pipeline linear part [1]. Such structures consist of two symmetrical half-shells, which are pressed around the pipe outer surface during mounting to create tight contact (interference). As a rule, such operations are performed under the condition of inner pressure lowering in the main line.

It is known that contact pressure $\Delta P_{1}$ arising at sleeve mounting on the pipe has an important role in ensuring reliable operation of repaired section [2]. This is associated not only with force pressing of half-shells during assembly by various devices, but also additional redistribution of loads between pipe and sleeve walls at inner pressure increase from repair value $P_{\text {rep }}$ up to working pressure $P$ (Figure 1). As the assembly process involves multilayer welding of half-shells to each other by two parallel longitudinal butt welds, contact pressure $\Delta P_{\mathrm{sh}}$ arises additionally, as a result of deposited metal shrinkage.

(C) O.I. OLEJNIK, 2015
The objective of this work consists in determination through calculation of $\Delta P_{\text {sh }}$ value for evaluation of the degree of its influence on total level of contact pressure $\Delta P_{1}$.

Calculation was based on the idea of determination of reactive stresses $\sigma_{\mathrm{r}}$ in a closed shell, which arise after making the longitudinal welds and act in the circumferential direction $\left(\mathrm{Fi}^{-}\right.$ gure 2). Assuming that stresses $\sigma_{\mathrm{r}}$ are uniformly distributed across sleeve wall section, and con-

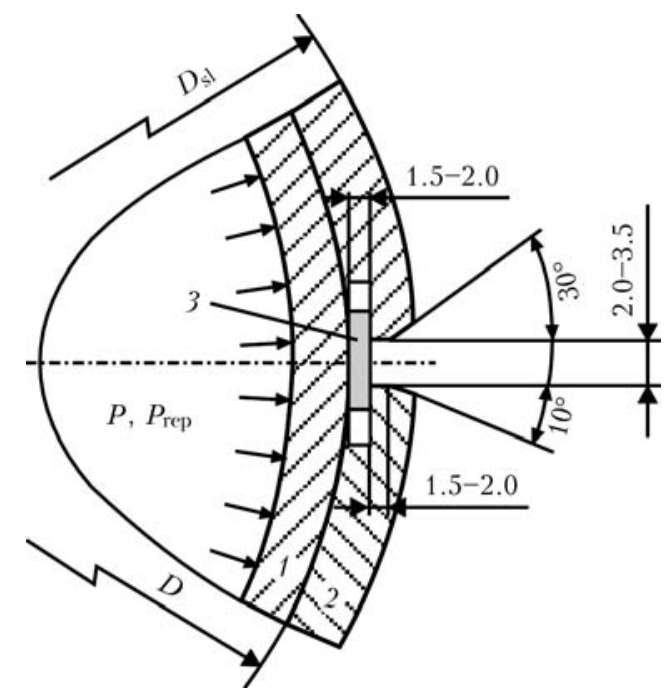

Figure 1. Schematic of edge preparation in sleeve half-shells for butt welding: 1,2 - pipe and sleeve wall; 3 - backing plate; $D, D_{\mathrm{sl}}$ - pipe and sleeve outer diameters, respectively; $P, P_{\text {rep }}-$ pressure inside the pipeline in working mode and during repair, respectively 


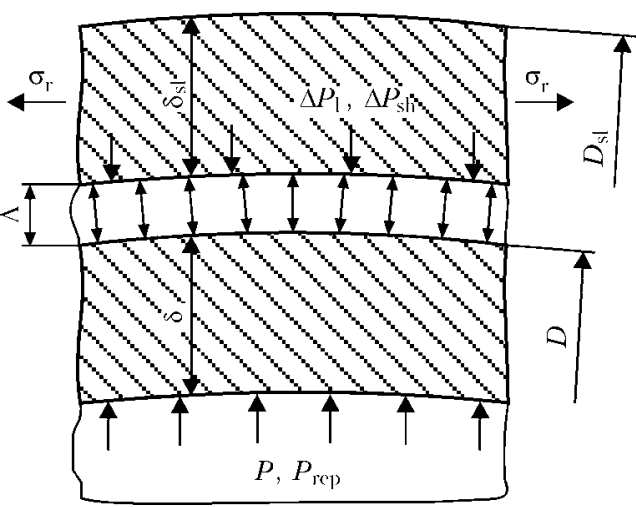

Figure 2. Stress-strain state of pipe and sleeve walls under the impact of inner pressure: $\delta, \delta_{\mathrm{sl}}-$ pipe and sleeve wall thickness, respectively; $\Delta P_{1}-$ contact pressure of sleeve on the pipe; $\Delta P_{\mathrm{sh}}-$ contact pressure of sleeve on the pipe caused by weld shrinkage

dition of dense contact $(\Lambda>>0)$ is fulfilled, average contact pressure $\Delta P_{\text {sh }}$ can be found from the following formula:

$$
\Delta P_{\mathrm{sh}}=\sigma_{\mathrm{r}} \frac{2 \delta_{\mathrm{sl}}}{D+2 \delta_{\mathrm{sl}}},
$$

where $D$ is the pipeline outer diameter; $\delta_{\mathrm{sl}}$ is the nominal thickness of sleeve wall.

Known from theoretical fundamentals of welded structure design [4] is the calculated dependence for calculation of reactive stresses for the cases of transverse location of welds relative to the action of reactive stresses:

$$
\sigma_{\mathrm{r}}=-\mu^{\prime} E \frac{q_{\mathrm{h} . \mathrm{i}}}{F}
$$

where $F$ is the welded element section in the direction normal relative to weld axis; $q_{\mathrm{h} . \mathrm{i}}$ is the average welding heat input; $E$ is the material modulus of elasticity; $\mu^{\prime}$ is the coefficient characterizing weld transverse shrinkage and determined by graphic dependence $\mu^{\prime}=f(m)$ ( Figure 3).

For the sleeve the section will be defined as

$$
F=\pi\left(D+2 \delta_{\mathrm{sl}}\right) \delta_{\mathrm{sl}} .
$$

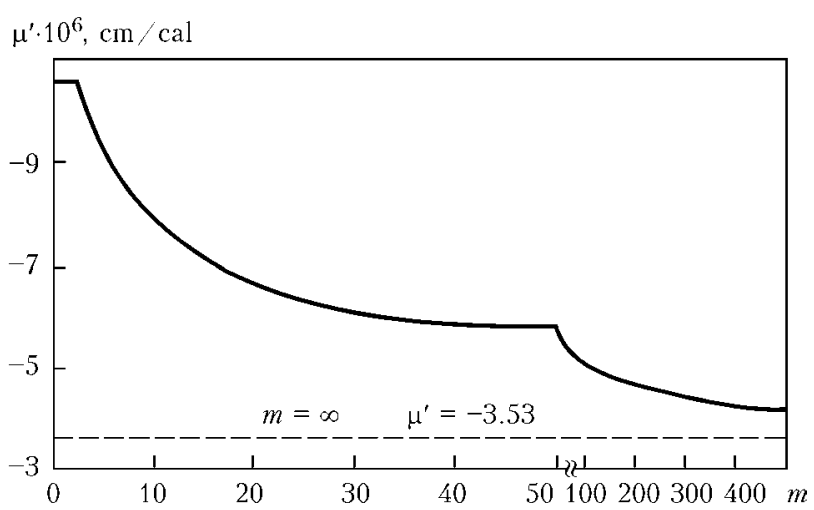

Figure 3. Coefficient $\mu^{\prime}$ versus relative rigidity $m$
Parameter $m$, which reflects relative rigidity, is calculated from the following formula for such a structure:

$$
m=0.125 \cdot 10^{6} \frac{4 F}{v_{\mathrm{w}} q_{\mathrm{h} . \mathrm{i}}^{2}},
$$

where $v_{\mathrm{w}}$ is the welding speed.

In butt welding in several passes the conditional heat input is calculated by the following formula:

$$
q_{\mathrm{con}}=340\left(F_{\mathrm{gr}}+\frac{2}{\cos \theta / 2} r \delta_{\mathrm{sl}}\right),
$$

where $F_{\text {gr }}$ is the area formed by butt weld groove; $\theta$ is the total groove angle; $r=43.5 \cdot 10^{-3} \sqrt[3]{q_{\mathrm{h} . \mathrm{i}}}$.

Considering that sleeve half-shells were welded to each other by two butt welds, formula (2) can be written as

$$
\sigma_{\mathrm{r}}=-\mu^{\prime} E \frac{2 q_{\text {con }}}{F} .
$$

Let us consider an example of calculation of the magnitude of contact pressure $\Delta P_{\mathrm{sh}}$ for the case of sleeve repair of corrosion damage with overall dimensions of $250 \times 150 \mathrm{~mm}$ in the longitudinal $S$ and circumferential $C$ directions and maximum depth $a=4 \mathrm{~mm}$. Pipe of X60 strength class of $D=1020 \mathrm{~mm}, \delta=10.5 \mathrm{~mm}$ was used with sleeve wall thickness $\delta_{\mathrm{sl}}=10.5 \mathrm{~mm}(\delta=$ $\left.=\delta_{\mathrm{sl}}\right)$. For calculation we will assume the following welding mode, characteristic for $4 \mathrm{~mm}$ electrode: $I=140 \mathrm{~A}, U=24 \mathrm{~V}, \eta=0.7, v_{\mathrm{w}}=$ $=0.2 \mathrm{~cm} / \mathrm{s}$.

Then, $q_{\mathrm{h} . \mathrm{i}}=0.24 I U \eta\left(v_{\mathrm{w}}\right)^{-1}=2822[\mathrm{cal} / \mathrm{cm}]$; $r=2.31 \mathrm{~cm} ; F_{\mathrm{gr}}=0.44 \mathrm{~cm}^{2}$.

We will determine welded element section in the normal direction from formula (3)

$$
\begin{gathered}
F=\pi\left(D+2 \delta_{\mathrm{sl}}\right) \delta_{\mathrm{sl}}= \\
=\pi(102+2 \cdot 1.05) \cdot 1.05=244 \mathrm{~cm}^{2} .
\end{gathered}
$$

We will calculate conditional heat input by formula (5), considering that groove angle $\theta=$ $=40^{\circ}$ and $q_{\mathrm{con}}=340\left(0.53+2 \cdot 2.31 \cdot 1.05\left(\cos 20^{\circ}\right)^{-1}=\right.$ $=1905 \mathrm{cal} / \mathrm{cm}$.

Sleeve relative stiffness is equal to

$$
m=0.125 \cdot 10^{6} \frac{4 F}{v_{\mathrm{w}} q_{\mathrm{h} . \mathrm{i}}^{2}}=108 .
$$

Then, the coefficient, which determines weld transverse shrinkage, will correspond to value $\mu^{\prime}=-4 / 97 \cdot 10^{-6} \mathrm{~cm} / \mathrm{cal}$.

Reactive stress magnitude in keeping with (6) is equal to 


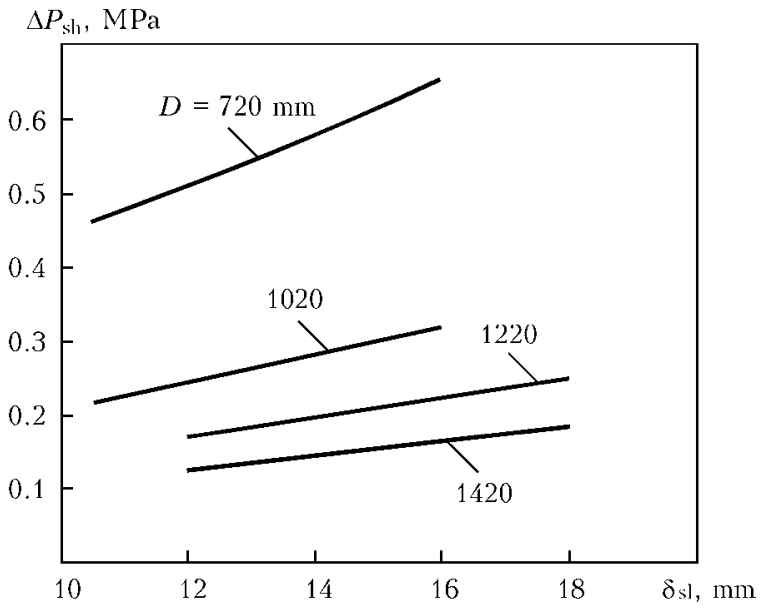

Figure 4. Influence of sleeve wall thickness $\delta_{\mathrm{sl}}$ on magnitude of contact pressure caused by longitudinal weld shrinkage $\Delta P_{\text {sh }}$ depending on pipeline diameter $D$

$$
\sigma_{\mathrm{r}}=-\mu E \frac{2 q_{\mathrm{con}}}{F}=110 \mathrm{~kg} / \mathrm{cm}^{2} .
$$

Magnitude of average contact pressure between the sleeve and pipe $\Delta P_{\mathrm{sh}}$ is determined as $\Delta P_{\mathrm{sh}}=\sigma_{\mathrm{r}} \frac{2 \delta_{\mathrm{sl}}}{D+2 \delta_{\mathrm{sl}}}=2.22 \mathrm{~kg} / \mathrm{cm}^{2}$ or $\Delta P_{\mathrm{sh}}=0.22 \mathrm{MPa}$.

Figure 4 presents in the graphic form the results, obtained with application of the above calculation method, showing the dependence of $\Delta P_{\text {sh }}$ on sleeve wall thickness $\delta_{\mathrm{sl}}$ and pipeline diameter $D$. To evaluate the degree of $\Delta P_{\text {sh }}$ influence on level of contact pressure $\Delta P_{1}$ it is necessary to have the diagrams of admissible linear dimensions of pipe wall thinning, the sample of which is shown in Figure 5, and criterion of grounded selection of $\Delta P_{1}$ value. The latter has the following form [5]:

$$
\Delta P_{1} \geq P-[P]-\chi_{1}\left(P-P_{\text {rep }}\right),
$$

where $[P]$ is the admissible pressure for pipe wall thinning, determined by diagrams of admissible linear dimensions;

$$
\chi_{1}=\left(1+\frac{\left(0.5 D_{\mathrm{sl}}\right)^{2} \delta}{(0.5 D)^{2} \delta_{\mathrm{sl}}}\right)^{-1} .
$$

In view of the requirements of normative documents on repair in operating gas pipelines that $P_{\text {rep }}=0.7 P(P=5.4 \mathrm{MPa})$, for the considered example $\left[P \overline{]}=0.75 P, \chi_{1}=0.49\right.$. Then, in keeping with (7), $\Delta P_{1}=0.55 \mathrm{MPa}$. Comparing the calculated value with $\Delta P_{\text {sh }}=0.22 \mathrm{MPa}$, one can say that in this case contact pressure caused by longitudinal weld shrinkage makes up a significant part (about $40 \%$ ) of minimum required contact pressure. Their total value contributes to the margin for ensuring the performance of gas pipeline section repaired using the welded sleeve.

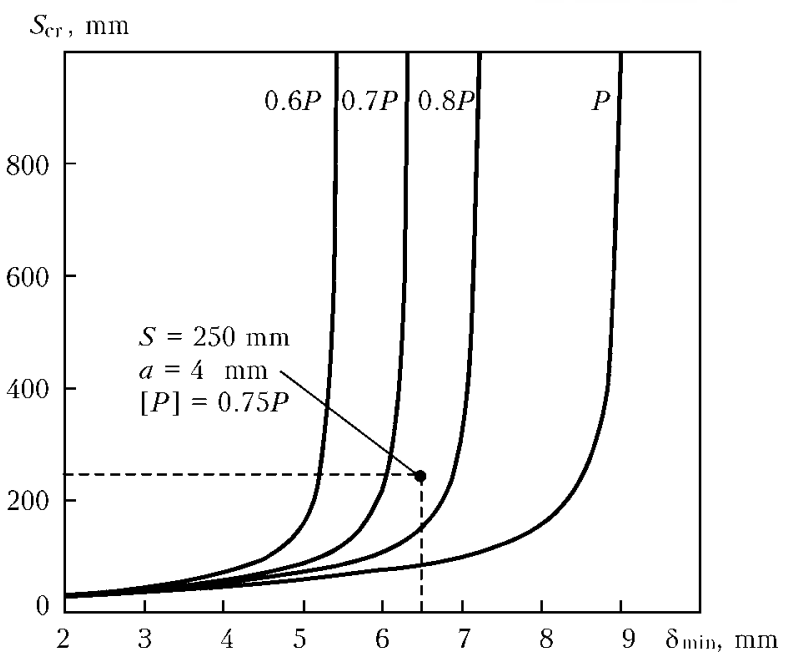

Figure 5. Diagram of admissible linear dimensions of pipe wall thinning depending on pipe wall minimum thickness $\delta_{\text {min }}$ for $1020 \times 10.5 \mathrm{~mm}$ gas pipeline from steel of strength category X60 with maximum working pressure $P=5.4 \mathrm{MPa}$

At the same time, it should noted that with increase of pipe diameter $D$, value of admissible pressure $[P]$ will decrease for a defect with the same overall dimensions, that will require increasing the minimum needed contact pressure $\Delta P_{1}$, accordingly. This leads to the conclusion about a decreasing role of $\Delta P_{\text {sh }}$.

Thus, it can be stated that shrinkage in welding of sleeve longitudinal welds on gas pipelines with outer diameter of $1020 \mathrm{~mm}$ and less will have the strongest influence on unloading of pipe defective wall. In repair of the main gas pipelines with $1220 \mathrm{~mm}$ and greater outer diameters, attention should be focused on providing the required value of contact pressure $\Delta P_{1}$, while influence of value $\Delta P_{\text {sh }}$ should be regarded as insignificant. A certain increase of $\Delta P_{\text {sh }}$ value can be achieved by increasing sleeve wall thickness $\delta_{\mathrm{s} l}$. Such a technique, however, has quite limited practical application, as a result of deterioration of mounting conditions, because of half-shell rigidity and complexity of ensuring the required value of contact pressure $\Delta P_{1}$.

1. GBN V.3.1-00013741-12:2011: Main gas pipelines. Repair by arc welding in service conditions. Kiev: Ministry of Energy and Coal Industry of Ukraine. Introd. 06.09.2011.

2. Kiefner, J.F. (1977) Repair of line pipe defects by full-encirclement sleeves. Welding J., 6, 26-34.

3. Aginej, R.V., Puzhajlo, A.F., Aleksandrov, Yu.V. et al. (2012) Methods of safety assurance of long-term service gas pipelines prone to stress-corrosion. Korroziya Territorii Neftegaz, 23(3), 50-61.

4. Okerblom, N.O. (1964) Structural-technological design of welded structures. Moscow-Leningrad:

5. Makhnenko, V.I., Olejnik, O.I., Shekera, V.M. (2013) Determination of contact pressure of reinforcing sleeve in repair of pipelines with surface defects. The Paton Welding J., 6, 11-14. 